408

http://dx.doi.org/10.1590/0100-2945-270/13

\title{
ATIVIDADE ANTITRÍPTICA DE PROTEÍNAS EM POLPAS E SEMENTES DE FRUTAS TROPICAIS ${ }^{1}$
}

\author{
ÁGNES DENISE DE LIMA BEZERRA², CLAUDIA RENATA MONTENEGRO BARBOSA ${ }^{2}$ \\ FABIANA MARIA COIMBRA DE CARVALHO ${ }^{2}$, ALEXANDRE COELHO SERQUIZ ${ }^{3}$, \\ ANA HELONEIDA DE ARAÚJO MORAIS²
}

RESUMO - A alimentação saudável e diversificada é essencial para a manutenção da saúde física e mental, e apesar de o perfil alimentar atual valorizar a praticidade do comer, nota-se que a população está consumindo, de forma crescente, frutas, tanto na forma in natura como na forma de sucos. No entanto, o consumo de certas frutas in natura ocorre acompanhado da ingestão de suas sementes, cascas ou mesmo outras partes, podendo existir fatores antinutricionais, moléculas e/ou compostos que podem interferir na biodisponibilidade e/ou digestibilidade de nutrientes, tais como os inibidores de tripsina. Tais inibidores podem prejudicar o aproveitamento de proteínas presentes nos alimentos, porém estudos recentes vêm sendo divulgados, demonstrando também os efeitos benéficos dos mesmos. Este estudo teve como objetivo avaliar inibidores de tripsina nos extratos aquosos das frutas: goiaba (Psidium guajava L), das variedades Kumagai (branca) e Paluma (vermelha); maracujá- amarelo (Passiflora edulis f.) e melancia (Citrullus vulgaris Schrad). Para tal, foi realizada a detecção da presença da atividade antitríptica e a dosagem de proteínas solúveis. Em todos os extratos analisados, foi detectada atividade inibitória de tripsina, bem como de proteínas solúveis. Assim, a inibição pode ser explicada pela presença de inibidores proteicos, pois, nos extratos de sementes, em SDS-PAGE, foi possível visualizar um largo espectro de bandas proteicas. Vale ressaltar que, no estudo, as bandas proteicas que coincidem com as massas moleculares dos inibidores de tripsina não apareceram de forma majoritária, demonstrando que os extratos de sementes, provavelmente, possuem inibidor proteico, no entanto em pouca quantidade, justificando a baixa atividade antitríptica (1,36 a 15,15 UI / $\mathrm{mg}$ de peso seco), também apresentada pelos extratos de polpa. Portanto, tendo em vista o consumo recomendado das frutas, incluindo goiaba, maracujá e melancia, possivelmente, esta atividade inibitória esteja mais relacionada a benefícios do que a prejuízos à saúde, enfatizando, entretanto, o cuidado com o consumo de quantidades elevadas de sementes presentes e consumidas nestas frutas.

Termos para indexação: Goiaba 'Kumagai', goiaba 'Paluma', Passiflora edulis f., Citrullus vulgaris Schrad, inibidor enzimático, proteínas.

\section{ANTITRYPTIC ACTIVITY OF PROTEINS FROM PULPS AND SEEDS OF TROPICAL FRUITS}

\begin{abstract}
A healthy and diversified eating is essential for the maintenance of physical and mental health, and despite the current trend that appreciates the convenience of eating, it is noted that the population is increasingly consuming fruit, both in natura and / or juices. However, the use of certain fresh fruits is accompanied by the consumption of the seeds, peels or other parts may contain antinutritional factors, molecules and / or compounds that may adversely affect the bioavailability and / or digestibility of nutrients, such as inhibitors of trypsin. Such inhibitors may impair the utilization of proteins in food, but recent studies have been published also demonstrating the beneficial effects of the same. This study aimed to evaluate the trypsin inhibitors in aqueous extracts of fruits: guava (Psidium guajava L) varieties Kumagai (white) and Paluma (red), yellow passion fruit (Passiflora edulis f.) and watermelon (Citrullus vulgaris Schrad). Tests were done in order to detect the presence of antitryptic activity and the dosage of soluble proteins. Trypsin inhibitory activity was detected in all extracts tested, as well as soluble proteins. Thus, inhibition can be explained by the presence of an inhibitor protein, because it was possible, in seed extracts, in SDS-PAGE, to visualize a wide range of protein bands. It is noteworthy that in the study, the protein bands that coincide with the molecular masses of the trypsin inhibitors did not appear in a majority, showing that seed extracts are likely to have protein inhibitor, however sparingly, justifying the low antitryptic activity (1,36 to $15.15 \mathrm{IU} /$ $\mathrm{mg}$ of dry weight), also shown by the extracts of the pulp. Therefore, having the recommended consumption of fruits including guava, passion fruit and watermelon in sight, possibly this inhibitory activity is more related to benefits than to hazards, regarding one's health. However, it is important to emphasize a careful consumption of large quantities of seeds present in these fruits.

Index terms: Guava 'Kumagai', 'Paluma' guava, Passiflora edulis f., Citrullus vulgaris Schrad, enzyme inhibitor, protein.

${ }^{1}$ (Trabalho 270-13). Recebido em: 05-08-2013. Aceito para publicação em: 25-03-2014.

${ }^{2}$ IC, IC, IC, Prof. Dr., Depto de Nutrição, UFRN, E-mails: fabicoimbra@hotmail.com, claudia barbosa nutricao@hotmail.com; agnes_denise@hotmail.com; aharaujomorais@gmail.com.

${ }^{3}$ Ms., Dr., Depto de bioquímica, UFRN, E-mails: alexandreserquiz@gmail.com; elizeu@elizeu@ufrnet.br
\end{abstract}




\section{INTRODUÇÃO}

Com os maus hábitos alimentares da população, os riscos de doenças crônicas não transmissíveis estão aumentando no Brasil (BRASIL, 2010). Hão de se propor dietas que estejam ao alcance de todos, e que tenham um impacto sobre os mais importantes fatores relacionados às várias patologias. Sendo assim, recomendar o consumo de frutas, verduras, cereais e legumes, assim como evitar doces, gorduras saturadas, sal em excesso e alimentos calóricos, é o mais indicado. A goiaba (Psidium guajava L.), o maracujá-amarelo (Passiflora edulis f.) e a melancia (Citrullus vulgaris Schrad) são exemplos de frutas consumidas no Brasil, geralmente in natura ou na forma de sucos, que merecem destaque quanto às suas alegações de saúde. Estas frutas destacam-se entre as frutas tropicais, pois, além de saborosas e nutritivas, apresentam potencial para várias finalidades, sendo a ação antioxidante a mais estudada (MELO et al., 2008; COSTA; MONTEIRO, 2009; ZERAIK et al., 2010).

Para além dos benefícios já claramente elucidados de uma alimentação saudável, as novas linhas de pesquisa voltam-se em busca de esclarecer complexos mecanismos de ação de moléculas e compostos alimentares específicos e seus efeitos fisiológicos sobre o organismo. Nessa vertente, os inibidores de serinoproteases, amplamente distribuídos nos alimentos de origem vegetal (CHEVREUIL et al., 2009), destacam-se por uma atuação que se consolida no ramo de pesquisas, buscando claramente elucidar seus complexos mecanismos de ação. Estes, no trato intestinal, atuam inibindo a ação de enzimas digestivas, como a tripsina, que são responsáveis pela digestão das proteínas dietéticas, sendo, em animais, constatado que estes inibidores provocam o aumento do pâncreas (hipertrofia e hiperplasia) e hipersecreção de enzimas digestivas (BARROS et al., 2008; DUARTE et al., 2010). Entretanto, estudos citam não serem maléficas estas alterações no pâncreas por serem transitórias (CHEN et al., 2012). No entanto, o estudo das funções biológicas destes inibidores avança junto com a descoberta de suas aplicabilidades, tais como na modulação da carcinogênese (STENMAN, 2011), na resposta inflamatória (ROY et al., 2010; MONTEIRO, 2011; MACHADO et al., 2013), na coagulação, na angiogênese e nas propriedades antifúngicas (WONG et al., 2010). Uma das áreas em crescimento é o estudo de sua aplicabilidade no combate a doenças como obesidade, devido à constatação de que a presença de proteínas não digeridas no lúmen intestinal ativa, mediado pelo peptídeo monitor, um mecanismo de estimulação da produção de um hormônio de caráter sacietogênico, a colecistoquinina (KOMARNYTSKY et al., 2011; NAKAJIMA et al., 2011).

Nos alimentos de origem vegetal, inclusive nas frutas e em suas polpas, os inibidores proteicos de enzimas também estão presentes, mas apresentam-se predominantemente em sementes e em leguminosas (CHEVREUIL et al., 2009).

Desta forma, detectar e avaliar inibidores de tripsina nas frutas: goiaba-branca e vermelha; maracujá e melancia é uma estratégia que visa a gerar dados que tanto podem estar relacionados às qualidades nutricionais presentes nestas frutas, quanto à sua segurança quando ingeridas.

\section{MATERIAL E MÉTODOS}

As goiabas (Psidium guajava L.) das variedades Kumagai (branca) e Paluma (vermelha), o maracujá-amarelo (Passiflora edulis f.) e a melancia (Citrullus vulgaris Schrad) foram obtidos comercialmente na cidade de Natal-RN. Os experimentos foram desenvolvidos no Laboratório de Química de Proteínas Bioativas Prof. Maurício Pereira de Sales, do Departamento de Bioquímica da UFRN.-

Para o Preparo do extrato bruto aquoso de polpa e de semente das frutas, elas foram descascadas e tiveram sua polpa e suas sementes extraídas manualmente. Cada fruta constituiu-se de polpa de fruta e semente. Para o preparo dos extratos brutos aquosos das variedades de cada fruta, as sementes foram secas em estufa ventilada a $45^{\circ} \mathrm{C}$ e, em seguida, trituradas em moinho industrial resfriado $\left(6^{\circ} \mathrm{C}\right)$. Com granulação de aproximadamente 40 mesh, a polpa de fruta foi triturada em liquidificador doméstico. Em seguida, estas foram pesadas e submetidas à extração, que ocorreu em tampão Tris-HCL 0,05 mM, pH 7,5 , na proporção $1: 10(\mathrm{p} / \mathrm{v})$ sob 3 horas de agitação constante. Após a agitação, foram centrifugadas a 4 ${ }^{\circ} \mathrm{C}$, durante 30 minutos, na frequência de $8.000 \mathrm{x} g$. Em seguida, a solução heterogênea obtida foi filtrada com auxílio de funil e algodão, e o sobrenadante, denominado extrato bruto.

As atividades inibitórias de tripsina, nos extratos das variedades de cada fruta, foram medidas em triplicata e determinadas como descrito por Kakade et al. (1969), com uso do substrato BAPNA $0,0125 \mathrm{mM}$. O resultado foi mensurado por meio de leitura em espectrofotômetro a $410 \mathrm{~nm}$. Os resultados foram expressos em UI (unidade de inibição) / mg de peso seco da amostra, em que a unidade de inibição representa a diferença entre a atividade enzimática da enzima (controle) e dos testes (extratos), sendo $1 \mathrm{UI}$ igual a $0,01 \mathrm{~nm}$. 
Todas as determinações proteicas das variedades de cada fruta foram medidas em triplicata e realizadas pelo método de Bradford (1976). As leituras das absorbâncias foram realizadas a $595 \mathrm{~nm}$ em espectrofotômetro. Os resultados foram expressos em $\mu g$ de proteínas solúveis/ $\mu \mathrm{L}$ de extrato.

A eletroforese em gel de poliacrilamida desnaturante a $15 \%$ (SDS-PAGE) foi realizada apenas para os extratos que continham proteínas, sendo realizada pelo método desenvolvido por Laemmli (1970). Após a eletroforese, o gel foi corado e descorado segundo procedimento descrito por Weber e Osborn (1969). Na eletroforese, foi utilizado o marcador Unstained Protein Molecular Weight Marker com massas moleculares: $116 \mathrm{kDa}$ de $\beta$-galactosidase, 66,2 kDa de Albumina Serum Bovina, $45 \mathrm{kDa}$ de Ovoalbumina, $35 \mathrm{kDa}$ de Lactato Desidrogenase, 25 $\mathrm{kDa}$ de REase Bsp98I, 18,4 kDa de $\beta$ - lactoglobulina e 14,4 kDa de Lisosima.

Os dados foram tabulados e analisados por meio de estatística descritiva, usando medidas de tendência central e de dispersão (desvio-padrão), utilizando o programa Microsoft Excel ${ }^{\circledR}$, versão XP.

\section{RESULTADOS E DISCUSSÃO}

Já se conhece que tanto os inibidores de origem proteica quanto os compostos fenólicos interferem na atividade de algumas enzimas e inibem ou reduzem a digestão proteica e, assim, a absorção dessas (CONCEIÇÃO et al., 2010), muito embora a literatura também nos forneça informações sobre as funções benéficas que esses inibidores podem desempenhar.

$\mathrm{Na}$ avaliação da atividade inibitória de tripsina, pôde-se constatar que, em todos os extratos de frutas analisados, foi detectada atividade antitríptica. Entretanto, os resultados das atividades inibitórias de tripsina dos extratos de polpa e semente, em cada fruta, goiaba- vermelha, goiaba-branca, maracujá e melancia, revelaram que o extrato de polpa da goiababranca e o extrato de semente da goiaba-vermelha apresentaram maior atividade antitríptica comparada aos demais extratos, como pode ser observado nos Gráficos 1 e 2, respectivamente.

Já era esperado encontrar essa atividade de inibição nas polpas de frutas (ARAÚJO et al., 2004) e, principalmente, nas sementes (CHEVREUIL et al., 2009), visto que tal fato já é bastante claro e repercutido na literatura. Tem-se, ainda, que esses inibidores, para melhor conhecimento dos mesmos, têm sido detectados e, tão logo, isolados e purificados (SANTOS et al., 2012).
Os resultados referentes à dosagem de proteínas, isto é, à quantidade de proteínas solúveis para todos os extratos de goiaba-branca, goiaba-vermelha, melancia e maracujá, revelaram quantidades de proteínas solúveis. Quanto à melancia e ao maracujá, seus extratos de semente apresentaram maior quantidade de proteínas solúveis ao serem comparados com os demais extratos. No tocante aos extratos de polpa, o maracujá e a goiaba-vermelha apresentaram maiores quantidades de proteínas solúveis ao serem comparados com os demais extratos, como pode ser observado no Gráfico 3 e no Gráfico 4.

Ainda, os extratos de semente das duas goiabas, vermelha e branca, melancia e maracujá foram aplicados em SDS-PAGE e foi possível visualizar bandas proteicas na faixa de $\sim 60 \mathrm{kDa}$ e $\sim 14 \mathrm{kDa}$ (Figura 1).

De acordo com os resultados de dosagem proteica nos extratos, pôde ser observado que é nos extratos de sementes das frutas que houve maior quantidade de proteínas solúveis quando comparados com os extratos de polpa, sendo maior na semente de maracujá. Entretanto como o extrato de semente de maracujá apresentou esse maior conteúdo de proteínas, esperava-se visualizar estas proteínas em SDS-PAGE com massas moleculares similares aos inibidores de tripsina já purificados.

Ressalta-se que a massa molecular desses inibidores pode variar de 4 a $85 \mathrm{kDa}$, com a maioria na faixa de 8 a $20 \mathrm{kDa}$ (SANTOS et al., 2012). A SDS-PAGE apresenta, neste estudo, nos extratos de sementes, proteínas majoritárias com massas moleculares variando na faixa de $60 \mathrm{kDa}$ a $14 \mathrm{kDa}$, no entanto não coincidem com massas moleculares de inibidores de tripsina de sementes publicados na literatura, tais como os do tipo Kunitz, e dentre eles o ApTKI de $22 \mathrm{kDa}$, da semente de Adenanthera pavonina L. (MIGLIOLO et al., 2010), o ByyTI de $21 \mathrm{kDa}$, da flor da planta Bauhinia variegata (FANG et al., 2010), o EvTI de $19 \mathrm{kDa}$, da semente de Erythrina velutina (MACHADO et al., 2013), além dos inibidores de tripsina das sementes de feijão-branco, vermelho, azuki, com massas de 132, 118 e 13 kDa, respectivamente (WATI et al., 2009).

Vale ressaltar que, no estudo, várias outras bandas proteicas apareceram com menor predominância no gel e coincidem com as massas dos inibidores de tripsina, demonstrando que o extrato de semente, provavelmente, possui inibidor proteico, no entanto em pouca quantidade, justificando a baixa atividade antitríptica (1,36 a 15,15 UI / mg de peso seco) quando comparados à soja, antes e depois da germinação, com valores de atividade inibitória variando de 181,93 a 169,98 UTI / mg de amostra 
(MARTINEZ et al., 2011). Vale ressaltar que cada $\mu \mathrm{L}$ de extrato de polpa das frutas analisadas continha apenas de 0,030 a $0,107 \mu \mathrm{g}$ de proteínas solúveis, enquanto cada $\mu \mathrm{L}$ de extrato de semente continha de 0,359 a 2,015 $\mu \mathrm{g}$ de proteínas solúveis, sendo pouco mais, no entanto muito inferior à quantidade de proteínas solúveis da soja (15 a $21 \mu \mathrm{g} / \mathrm{g}$ de massa seca de semente) (HENNING et al., 2010).

Dessa maneira, o interesse em inibidores de protease dá-se principalmente devido às suas altas concentrações na dieta de animais, podendo afetar os processos digestivos, influenciando em seu desenvolvimento e crescimento (CHEN et al., 2012), sabendo, portanto, que, para os seres humanos, inibidores enzimáticos não são um problema real, uma vez que o nível de atividade inibitória é reduzida, principalmente por meio do cozimento (FELIX et al., 2011). Além disso, os vários estudos relacionados aos efeitos benéficos de inibidores enzimáticos vêm sendo publicados, abrindo novas possibilidades na prospecção dessas moléculas biotivas.

Estudos feitos com feijão mostraram ter valores de atividade inibitória de tripsina variando de 5,71 a 25,14 UTI/ mg, além de 0,20 g de tripsina inibida/g amostra (CARDOSO, 2008; DUARTE et al., 2010), além de outros estudos com quinoa, mostrando a variação de atividade dependendo dos processos de germinação e diferentes tratamentos térmicos, podendo apresentar de 0,17 a 2,39 UTI/ mg (AMISTÁ; TAVANO, 2013); entretanto, esses são exemplos de amostras que apresentam altas quantidades de proteínas. Por sua vez, estudos realizados identificaram, em frutas e em amostras com baixas quantidades de proteínas solúveis, a presença de inibidores de tripsina, sendo na jabuticaba com valores de 1,58 a 6,42 UTI/mg ${ }^{1}$ MS (LIMA et al., 2008). Ainda, consoante estudos realizados por Araújo et al. (2004), com polpa de frutas tropicais, detectaram a presença de atividade antitríptica no açaí, mangaba, cajá, pitanga, acerola e cupuaçu. Os níveis de atividade inibitória foram relativamente baixos para a maioria dos frutos, sendo, entre esses, os que apresentaram maiores atividades: o açaí $(0,054$ $\mathrm{mg}$ de inibidor / $\mathrm{g}$ de polpa), a mangaba $(0,0395 \mathrm{mg}$ de inibidor/g de polpa) e a pitanga $(0,013 \mathrm{mg}$ de inibidor / g de polpa).

Mesmo diante da ação inibitória para tripsina, é importante lembrar que, na literatura, não existe nenhuma restrição severa para o consumo de goiabavermelha, goiaba- branca, melancia e maracujá; no entanto, deve-se ter atenção a cuidados relacionados ao consumo de quantidades elevadas de sementes presentes e consumidas nestas frutas.

Além disso, é importante destacar que tais inibidores presentes nas frutas podem apresentar ações benéficas. Dessa forma, detectar inibidores de tripsina em sementes e polpa de frutas é de grande relevância, sendo um tema de grande importância para a saúde, já que são frutas bastante consumidas por todos e principalmente pela possibilidade de gerar dados que podem ser utilizados na bioprospecção de novos bioprodutos a serem usados, como bioinseticidas, biofungicidas, bactericidas e também como biofármacos.

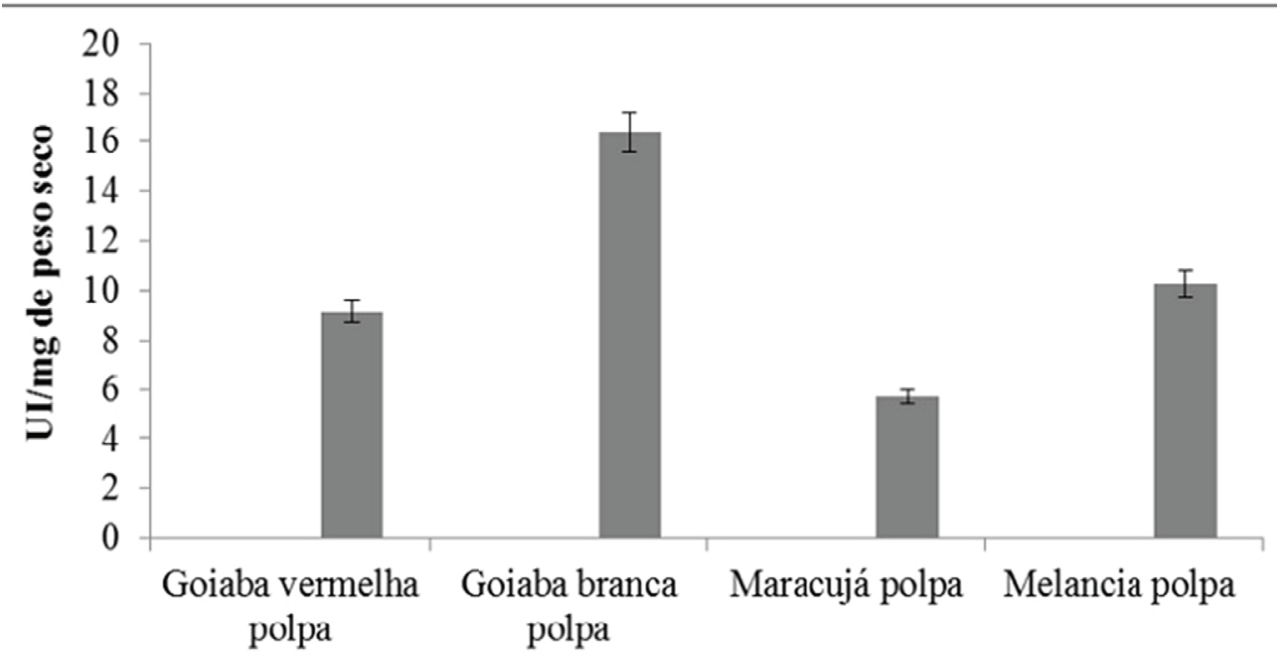

Frutas

GRÁFICO 1- Atividade inibitória de tripsina nos extratos de polpa das frutas, goiaba-vermelha, goiaba-branca, maracujá e melancia. Os dados são expressos em UI (unidade de inibição) / mg de peso seco e apresentados como média \pm desvio- padrão. 


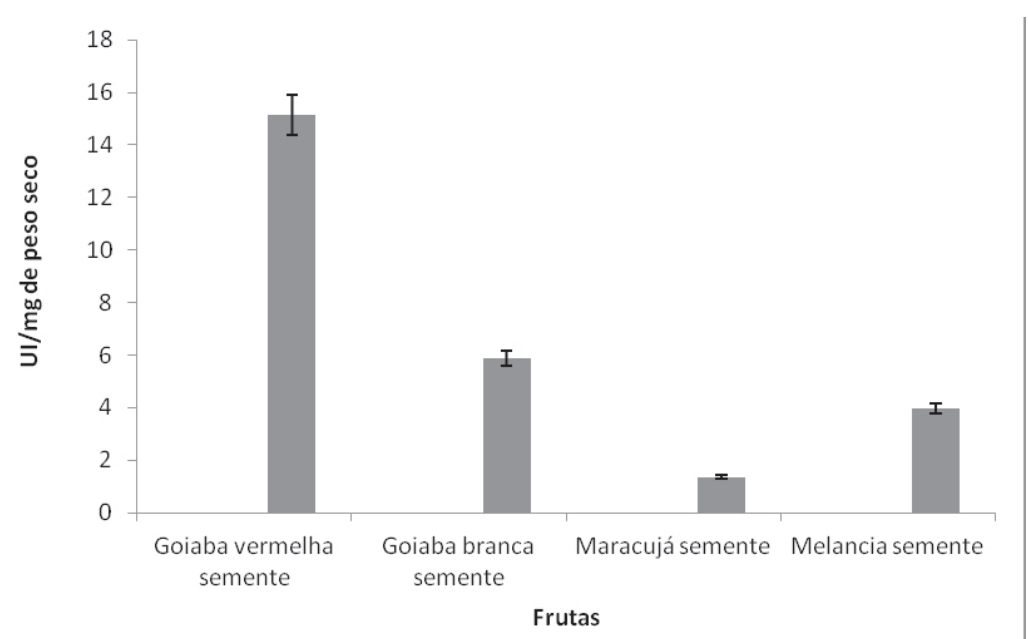

GRÁFICO 2- Atividade inibitória de tripsina nos extratos de semente das frutas, goiaba-vermelha, goiaba-branca, maracujá e melancia. Os dados são expressos em UI (unidade de inibição) / mg de peso seco e apresentados como média \pm desvio-padrão.

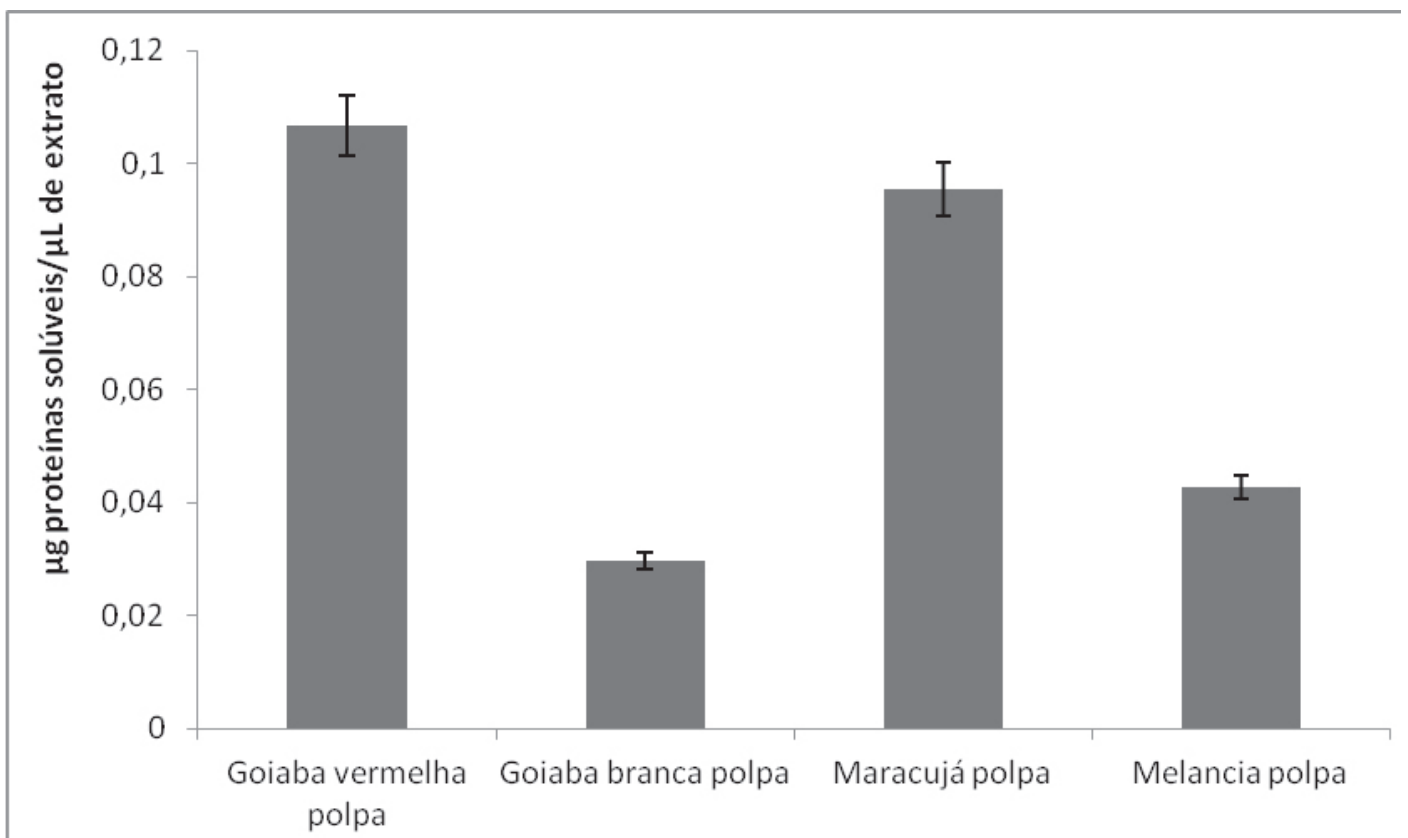

GRÁFICO 3- Conteúdo de proteínas solúveis nos extratos de polpa das frutas, goiaba-vermelha, goiaba-branca, maracujá e melancia. Os resultados foram expressos em $\mu \mathrm{g}$ de proteínas solúveis $/ \mu \mathrm{L}$ de extrato e apresentados como média \pm desvio-padrão. 


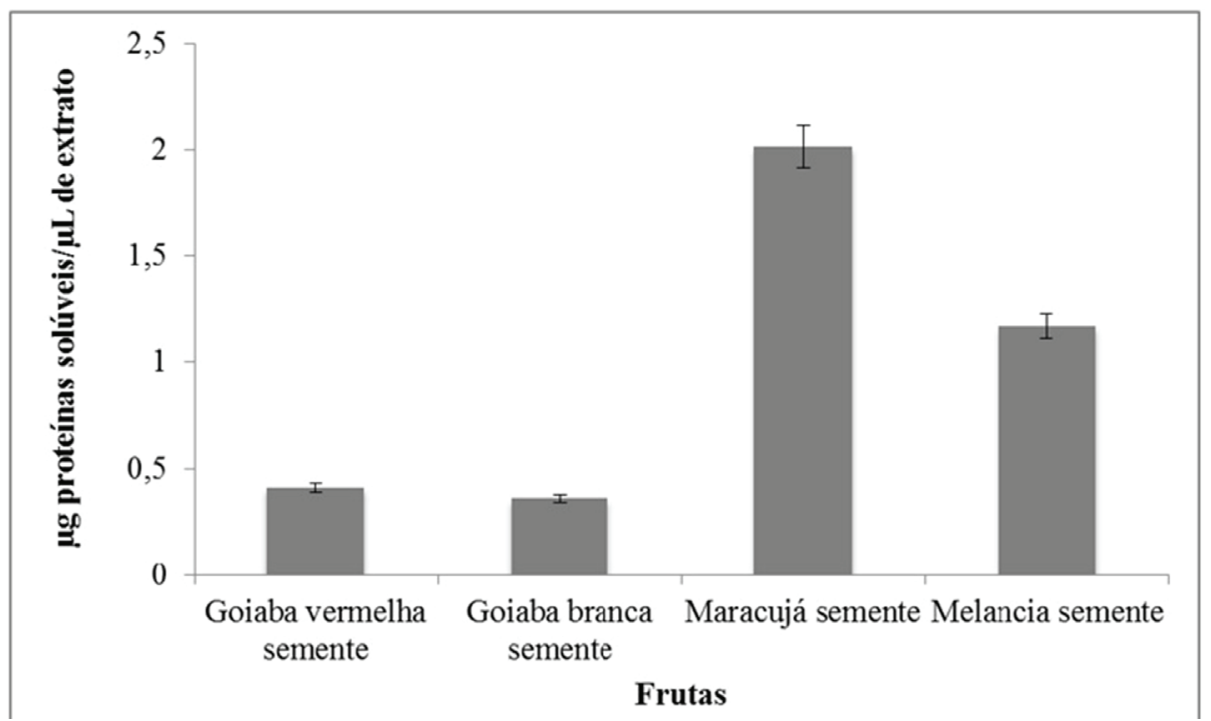

GRÁFICO 4- Conteúdo de proteínas solúveis nos extratos de semente das frutas, goiaba-vermelha, goiaba-branca, maracujá e melancia. Os resultados foram expressos em $\mu \mathrm{g}$ de proteínas solúveis/ $\mu \mathrm{L}$ de extrato e apresentados como média \pm desvio-padrão.

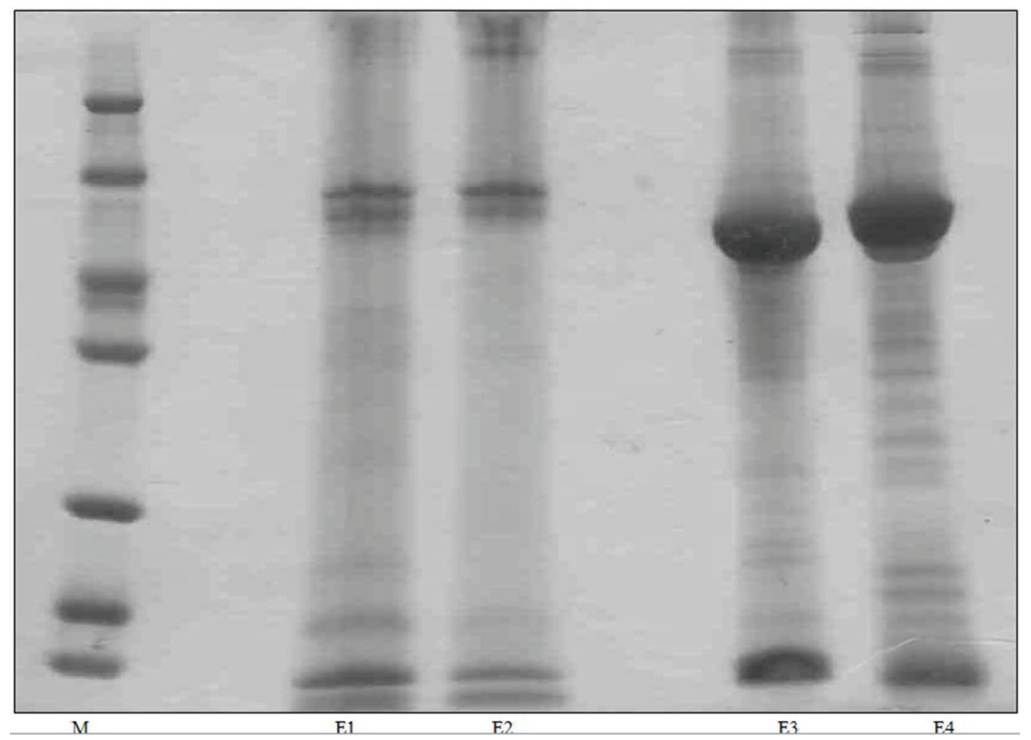

FIGURA 1- Eletroforese em gel de poliacrilamida desnaturante a 15\% (SDS-PAGE) de extratos de sementes de goiaba Paluma, de goiaba Kumagai, de melancia (Citrullus vulgaris Schrad) e de maracujá (Passiflora edulis f.). $\mathrm{M}=$ marcador (116 kDa de $\beta$-galactosidase, 66,2 kDa de Albumina Serum Bovina, $45 \mathrm{kDa}$ de Ovoalbumina, $35 \mathrm{kDa}$ de Lactato Desidrogenase, $25 \mathrm{kDa}$ de REase Bsp98I, 18,4 kDa de $\beta$ - lactoglobulina e 14,4 kDa de Lisosima); E1 = extrato de semente de goiaba Paluma (vermelha); E2 = extrato de semente de goiaba 'Kumagai' (branca); E3 = extrato de semente de melancia; E4 = extrato de semente de maracujá. 


\section{CONCLUSÃO}

1-Segundo os resultados, verificou-se, a partir do ensaio de atividade inibitória para tripsina, que houve a confirmação da presença de inibidores de tripsina em todos os extratos analisados das frutas em questão. Essa atividade foi mais pronunciada no extrato de polpa em goiaba-branca e de semente em goiaba-vermelha.

2-Ainda, foi realizada a dosagem de proteínas, e o extrato de todas as frutas apresentou concentrações de proteínas solúveis; no entanto, ao ser realizado o SDS-PAGE do extrato das sementes, as massas moleculares das proteínas mais evidentes, ao serem comparadas com a literatura, não coincidiram com massas moleculares de inibidores de origem proteica, comumente purificados e publicados.

3-Dessa maneira, apesar de os resultados demonstrarem a presença da atividade antitríptica em extratos de todas as frutas estudadas, não se pode prever a reprodutibilidade destes fenômenos in vivo, nem recomendar a redução do consumo dessas frutas que possuem muitos outros benefícios à saúde e dentro de um consumo adequado, provavelmente, sobrelevaria esses possíveis efeitos deletérios. Ademais, mais estudos seriam necessários para, de fato, confirmar a possibilidade de o inibidor ser apenas do tipo proteico.

\section{AGRADECIMENTOS}

In memoriam a Maurício Pereira de Sales, pelo incentivo ao desenvolvimento deste trabalho.

Ao Programa Institucional de Bolsas de Iniciação Científica - REUNI/UFRN, pela concessão das bolsas.

\section{REFERÊNCIAS}

AMISTÁ, M. J. M.; TAVANO, O. L. Influência da germinação e do processamento térmico na digestibilidade proteica e atividade de inibição de tripsina de grãos de quinoa. Brazilian Journal of Food technology, Campinas, v. 16, n. 1, p. 52-58, 2013

ARAÚJO, C. L.; BEZERRA, I. W. L.; DANTAS, I. C.; LIMA, T. V. S.; OLIVEIRA, A. S.; MIRANDA, M. R. A.; LEITE, E. L.; SALES, M. P. Biological activity of proteins from pulpls of tropical fruits. Food Chemistry, Oxford, v. 85, p.107-110, 2004.
BARROS, J. G.A.; MORAES, R. M.A.; PIOVESAN, N. D.; BARROS, E. G.; MOREIRA, M. A. Efeito do inibidor de protease Kunitz sobre níveis de lipoxigenases em sementes de soja. Ciência e Agrotecnologia, Lavras, v. 32, n. 4, p. 1.126-1.132, 2008.

BRADFORD, M. M. A rapid and sensitive method for the quantitation of microgram quantities of protein utilizing the principle of dye binding. Analytical Biochemistry, New York, v. 72, n. 1, p. 248-254, 1976.

BRASIL. Ministério do Planejamento, Orçamento e Gestão. Instituto Brasileiro de Geografia e Estatística. Pesquisa de Orçamentos Familiares 2008-2009: antropometria e estado nutricional de crianças, adolescentes e adultos no Brasil. Brasília: Ministério da saúde, 2010. 130 p. Disponível em: <http://www.ibge.gov.br/home/estatistica/ populacao/condicaodevida/pof/2008_2009_encaa/ pof 20082009 encaa.pdf $>$. Acesso em: 5 maio. 2013.

CARDOSO, L. M. Avaliação de alguns antinutrientes em variedades de feijões (Phaseolus vulgaris L.) cultivados no Vale do Jequitinhonha. In: CONGRESSO BRASILEIRO DE CIÊNCIA E TECNOLOGIA DE ALIMENTOS, 15., 2008, Belo Horizonte. Anais... p.1-3.

CHEVREUIL, L. R.; GONÇALVES, J. F. C.; BARIANI, A.; RODRIGUES, J. V. F. C.; PANDO, S. C. Detecção de inibidores de tripsina e atividade hamaglutinante em sementes de laguminosas arbóreas da amazônia. Acta Amazonica, Manaus, v. 39, n. 1, p. 199-206, 2009.

CHEN, W.; HIRA, T.; NAKAJIMA, S.; TOMOZAWA, H.; TSUBATA, M.; YAMAGUCHI, K.; HARA H. Suppressive effect on food intake of a potato extract $($ Potein $\AA$ ) involving cholecystokinin release in rats. Bioscience, Biotechinology and Biochemistry, Tokyo, v. 76, n. 6, p. 1104-1109, 2012.

CONCEIÇÃO, L. L.; DUARTE, M. S. L.; PEREIRA, C. A. S.; SOUZA, E. C. G. Determinação da atividade in vitro de Inibidores de Tripsina em feijão (Phaseolus Vulgaris L.)-preto, albumina e globulina. Alimentos e Nutrição, Araraquara, v. 21, n. 3, p. 373-376, 2010. 
COSTA, P. R. F.; MONTEIRO, A. R. G. Benefícios dos antioxidantes na alimentação. Revista Saúde e Pesquisa, Maringá, v.2, n.1, p.87-90, 2009. Disponível em: <http://www.cesumar.br/pesquisa/periodicos/ index.php/saudpesq/article/view/996/727endereço eletrônico >. Acesso em: 10 maio. 2013.

DUARTE, M. S. L.; PEREIRA, C. A. S.; SOUZA, E. C. G.; CONCEIÇÃO, L. L. Determinação da atividade in vitro de inibidores de tripsina em feijão (Phaseolus vulgaris L.)-preto, albumina e globulina. Alimentos e Nutrição, Araraquara, v. 21, n. 3, p. 373-376, 2010 .

FANG, E.F.; WONG, J.H.; BAH, C.S.F.; LIN,P.; TSAO, S. W.; NG, T.B. Bauhinia variegate var. variegate trypsin inhibitor: From isolation to potencial medicinal applications. Biochemical and Biophysical Research Communications, Orlando, v.396, n.4, maio 2010.

FELIX, M. A.; BRAZACA, S. G. C.; MACHADO, F. M. V. F. Análise sensorial dos grãos de soja (Glycine $\max ($ L.) Merril) tostados por diferentes tratamentos. Ciência e Tecnologia de Alimentos, Campinas, v. 31, n. 1, p. 56-64, 2011.

HENNING, F. A.; MERTZ, L. M.; JÚNIOR, E. A. J.; MACHADO, R. D.; FISS, G.; ZIMMER, P. D. Composição química e mobilização de reservas em sementes de soja de alto e baixo vigor. Bragantia, Campinas, v. 69, n. 3, p. 727-734, 2010.

KAKADE, M. L.; SIMONS, N.; LIENER, I. E. An evaluation of natural vs. synthetic substrates for measuring the antitryptic activity of soybean samples. Cereal Chemistry, St. Paul, v. 46, n. 5, p. 518-526, 1969.

KOMARNYTSKY, S.; COOK, A.; RASKIN, I. Potato protease inhibitors inhibit food intake and increase circulating cholecystokinin levels by a trypsin-dependent mechanism. International Journal of Obesity, London, v. 35, n. 2, p. 236$243,2011$.

LAEMMLI, U. K. Cleavage of structural proteins during the assembly of the head of bacteriophage T4. Nature, London, v. 227, p. 680-685, 1970.
LIMA, A. J. B.; CORRÊA, A. D.; ALVES, A. P. C.; ABREU, C. M. P.; BARROS, A. M. D. Caracterização química do fruto jabuticaba (Myrciaria cauliflora Berg) e de suas frações. Archivos Latinoamericanos de Nutrición, Venezuela, v.58, n.4, p.416-421, 2008.

MACHADO, R. J. A.; MONTEIRO, N. K. V.; MIGLIOLO, L.; SILVA, O. N.; PINTO, M. S. F.; OLIVEIRA, A. S.; FRANCO, O. L.; KIYOTA, S.; BEMQUERER, M. P.; UCHOA, A. F.; MORAIS, A. H. A.; SANTOS, E. A. Characterization and pharmacological properties of a novel multifunctional kunitz inhibitor from Errythrina velutina seeds. PloS One, v. 8, n. 5, p. 1-14, 2013. Disponível em: $\leq$ http:// www.ncbi.nlm.nih.gov/pubmed/23737945> $>$. Acesso em: 18 dez. 2013.

MARTINEZ, A. P. C.; MARTINEZ, P. C. C.; SOUZA, M. C.; BRAZACA, S. G. C. Alterações químicas em grãos de soja com a germinação. Ciência e Tecnologia de Alimentos, Campinas, v. 31, n. 1, p. 23-30, 2011.

MELO, E. A.; MACIEL, M. I. S.; LIMA, V. L. A. G.; NASCIMENTO, R. J. Capacidade antioxidante de frutas. Revista Brasileira de Ciências Farmacêuticas, São Paulo, v. 44, n. 2, p. 193-201, 2008.

MIGLIOLO, L.; OLIVEIRA, A. S.; SANTOS, E. A.; FRANCO, O. L.; SALES, M. P. Structural and mechanistic insights into a novel non-competitive Kunitz trypsin inhibitor from Adenanthera pavonina L. seeds with double activity toward serine- and cysteine-proteinases. Journal of Molecular Graphics and Modelling, New York, v. 29, n. 2, p. 148-156, 2010. Disponível em: $<$ http://www.ncbi. nlm.nih.gov/pubmed/20816329>. Acesso em: 12 jul. 2013.

MONTEIRO, N. K. V. Avaliação das atividades antiinflamatória, anticoagulante e antiproliferativa do inibidor de quimotripsina das sementes deErythrina velutina (EvCI). 2011. 126f. Dissertação (Mestrado em Bioquímica) - Universidade Federal do Rio Grande do Norte, Caicó, 2011.

NAKAJIMA, S.; HIRA, T.; TSUBATA, M.; TAKAGAKI, K.; HARA, H. Potato Extract (Potein) Suppresses Food Intake in Rats through Inhibition of Luminal Trypsin Activity and Direct Stimulation of Cholecystokinin Secretion from Enteroendocrine Cells. Journal of Agricultural and Food Chemistry, Washington, v. 59, n. 17, p. 9491-9496, 2011. 
ROY, F.; BOYE, J. I.; SIMPSON, B. K. Bioactive proteins and peptides in pulse crops: Pea, chickpea and lentil. Food Research International, Essex, v. 43, n. 2, p. 432-442, 2010.

SANTOS, E. A.; OLIVEIRA, A. S.; RABÊLO, L. M. A.; UCHÔA, A. F.; MORAIS, A. H. A. Affinity Chromatography as a Key Tool to Purify Protein Protease Inhibitors from Plants. In: MAGDELDIN, S. Affinity chromatography. Croatia: InTech, 2012. p. 211-244. Disponível em: < http://www.intechopen. com/download/get/type/pdfs/id/33057>. Acesso em: 10 maio. 2013.

STENMAN, U. H. Role of the tumor-associated trypsin inhibitor SPINK1 in cancer development. Asian Journal of Andrology, Beijing, v. 13, p. 628629, 2011.

WATI, R. K.; THEPPAKORN, T.; BENJAKUL, S.; RAWDKUEN, S. Three-phase partitioning of trypsin inhibitor from legume seeds. Process Biochemistry, London, v.24, p.1307-1314, 2009.
WEBER, K.; OSBORN, M. The reliability of molecular weight determinations by dodecyl sulfatepolyacrylamide gel electrophoresis. Journal of Biological Chemistry, Baltimore, v. 244, n. 16, p. 4.406-4.412, 1969.

WONG, J. H.; NG, T. B.; CHEUNG, R. C.; YE, X. J.; WANG, H. X.; LAM, S. K.; LIN, P.; CHAN, Y. S.; FANG, E. F.; NGAI, P. H.; XIA, L. X.; YE, X. Y.; JIANG, Y.; LIU, F. Proteins with antifungal properties and other medicinal applications from plants and mushrooms. Applied Microbiology and Biotechnology, Berlin, v. 87, n. 4, p. 1.221-1.235, 2010 .

ZERAIK, M. L.; PEREIRA, C. A. M.; ZUIN, V. G.; YARIWAKE, J. H. Maracujá: um alimento funcional? Revista Brasileira de Farmacognosia, Curitiba, v. 20, n. 3, p. 459-471, 2010. 